\title{
Cryptogenic fibrosing alveolitis: pattern of disease in the lung
}

\author{
PH WRIGHT, M BUXTON-THOMAS, L KREEL, SJ STEEL \\ From the Departments of Medicine and Nuclear Medicine, St Thomas' Hospital, Department of Radiology, . \\ Newham District Hospital, and the London Chest Hospital, London
}

ABSTRACT The distribution of disease has been studied in 10 patients with histologically confirmed cryptogenic fibrosing alveolitis by means of computed tomography of the lungs, gallium 67 uptake scintigraphy, and ventilation and perfusion scintigraphy. The findings of computed tomography and scintigraphy showed no correlation with the UICC/Cincinnati grades of the plain chest radiographs, even when these were supplemented with information from lateral and oblique chest films. Computed tomography showed subpleural shadowing in every patient except one who had responded well to corticosteroid treatment. Subpleural shadowing was commoner in the inferior and posterior parts of the lung lobes and was commonest in the posterior lower subpleural areas. The central lung showed three types of change-firstly, a dense shadowing, which was sometimes associated with much increased gallium uptake; secondly, dilated smaller airways with small bullae, suggesting airway disease; and, thirdly, gross bullous change.

Lung biopsy may be indicated in cryptogenic fibrosing alveolitis to confirm the clinical diagnosis, ${ }^{1}$ and to assess the prognosis and chances of a response to corticosteroids. $^{2}$ The latter requires a detailed analysis of the histological picture. Some authors have felt that only open lung biopsy will yield enough tissue to give a sufficiently representative sample for this to be done. ${ }^{34}$ We found that small biopsy specimens obtained by the trephine seemed equally effective. ${ }^{5}$ The trephine is used to sample subpleural lung, usually of the right lower lobe, as in all our cases. ${ }^{6-8}$ We therefore decided to investigate the distribution of changes within the lungs of living patients with alveolitis, to see why this site should be so useful for biopsy.

\section{Methods}

Ten patients were studied. Seven came from our previous survey, two were diagnosed later after trephine lung biopsy, and one was diagnosed at St Thomas' Hospital after open biopsy. We used the

Address for reprint requests: Dr PH Wright, Sandwell Chest Clinic, Heath Lane Hospital, West Bromwich, West Midlands B71 2BQ.

Accepted 18 May 1984 same histological criteria for diagnosis as in our previous study. ${ }^{5}$ All patients gave informed consent to the investigations for this study. Routine posteroanterior, lateral, and $45^{\circ}$ oblique chest radiographs were taken of each patient and assessed in two stages. Firstly, an experienced reader who read the films for our previous study graded the posteroanterior films according to the UICC/Cincinnati scheme. ${ }^{9}$ The films were presented for reading in random order with routine preoperative films of patients without lung disease as control films. The names and dates on the films were obscured and the reader had no information about the patients. Secondly, the other films were examined to see if they added any further information about the nature and distribution of radiographic change.

Computed tomography of the lungs was performed with a general purpose scanner (EMI 5005) at St Thomas' Hospital. ${ }^{10}$ Patients with abnormalities confined to the dorsal segments were scanned lying prone as well as supine to make certain that positioning was not responsible for this finding. One of us (LK) interpreted the computed tomographic images without access to other information about the patients. For presentation of the findings a three dimensional division of each lung into 12 parts was made (fig 1). Three horizontal zones were 


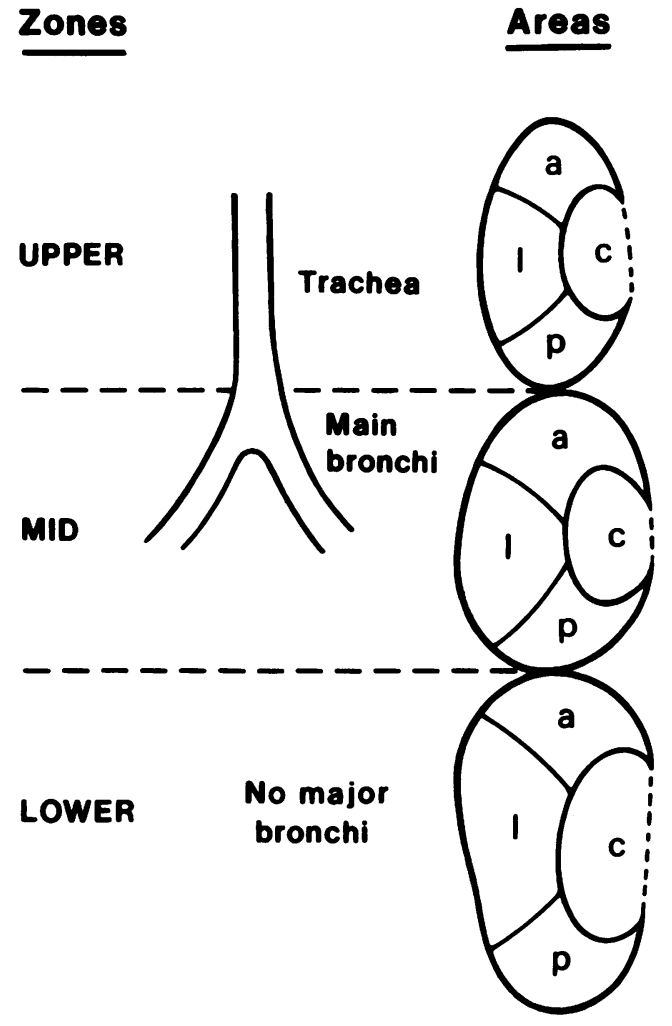

recognised-an upper zone with the trachea, a mid zone with the two main bronchi, and a lower zone with no large airways seen. Each of these zones was then divided into four areas-central, anterior, lateral, and posterior subpleural (fig 1).

Ventilation scintigraphs were obtained at $30 \mathrm{sec}-$ ond intervals while the subjects took a single breath of air to which $3 \mathrm{mCi}$ of xenon 133 gas had been added. Photographs of the inspiratory phase, during a period of breath holding, and expiration were available for analysis. They were examined for the overall inspiratory distribution and for any evidence of abnormal retention after the first minute in the washout phase.

Perfusion images made after intravenous injection of human albumin microspheres labelled with $3 \mathrm{mCi}$ of technetium $99 \mathrm{~m}$ were examined for the overall distribution of tracer, and each lung zone was
Fig 1 Division of the lungs into zones and areas for assessing the distribution of changes on computed tomography scans. a-anterior; $l$-lateral; $p \longrightarrow$ posterior; c-central. examined for perfusion defects. Gamma camera images were made 48 hours after injection of $2 \mathrm{mCi}$ of gallium 67 citrate. Anterior and posterior views were assessed for the overall distribution of tracer, and each lung zone was given an intensity score of $0 \cdot 4$. One of us (MB-T) interpreted the isotope scans without access to any other details of the patients.

The total radiation dose for each patient was calculated and ethical permission for the project was obtained from the Research (Endowments) Committee of St Thomas' Hospital.

\section{Results}

The UICC gradings for the patients are shown in table 1 , with readings from our previous survey, which was larger. Two patients in this study had normal films, but both had had abnormal ones

Table 1 UICC/Cincinnati grade of the 10 patients in this survey compared with 62 previously reported

\begin{tabular}{|c|c|c|c|c|c|c|c|c|}
\hline \multirow[t]{2}{*}{ No of cases } & \multicolumn{3}{|c|}{ Opacity size } & \multicolumn{4}{|c|}{ Opacity profusion } & \multirow{2}{*}{$\begin{array}{l}\text { Mean No of } \\
\text { affected zones }\end{array}$} \\
\hline & $s$ & $t$ & $u$ & 0 & 1 & 2 & 3 & \\
\hline $\begin{array}{l}62 \\
10\end{array}$ & $\begin{array}{r}21 \\
3\end{array}$ & $\begin{array}{r}23 \\
4\end{array}$ & $\begin{array}{r}12 \\
1\end{array}$ & $\begin{array}{l}3 \\
2\end{array}$ & $\begin{array}{r}17 \\
2\end{array}$ & $\begin{array}{r}25 \\
3\end{array}$ & $\begin{array}{r}11 \\
3\end{array}$ & $\begin{array}{l}4 \\
4\end{array}$ \\
\hline
\end{tabular}


Table 2 Number of patients with shadowing in each subpleural area

\begin{tabular}{llllllll}
\hline & \multicolumn{3}{l}{ Right lung } & & \multicolumn{3}{l}{ Left lung } \\
\cline { 2 - 3 } \cline { 6 - 8 } & $a$ & $l$ & $p$ & & $p$ & $l$ & $a$ \\
\hline Upper zone & 1 & 1 & 4 & & 0 & 1 \\
Middle zone & 1 & 2 & 7 & 6 & 2 & 3 \\
Lower zone & 4 & 4 & 7 & & 8 & 6 & 4 \\
\hline
\end{tabular}

a-anterior; -lateral; p-posterior.

before corticosteroid treatment. All the control films were identified as normal (0/0 or $0 /-)$. Examination of the lateral and oblique views added no further information about the type, extent, or distribution of shadowing.

One patient, with a normal chest radiograph, had normal appearances on computed tomography. The remainder all showed subpleural shadowing in both prone and supine views. The shadowing was not uniformly present over the whole of the lungs, and table 2 shows how it was distributed between the areas described under "Methods." Subpleural shadowing was absent in only five of 20 posterior lower areas studied; two were from the patient with normal appearances on the chest radiograph and computed scan, two were from a patient with such severe bullous change that no subpleural layer could be seen, and the fifth was from a patient with similar, though lesser, changes and a large bulla in the right posterior lower area. The positive findings recorded for the posterior middle areas are due to shadowing in the bases of the upper lobes and not the apices of the lower lobes, which were all free from shadowing.

All eight patients with abnormal radiographs showed changes in the central lung computed tomography scan. Table 3 and figure 2 show the different types of change seen. Although there were gradations between these types in individual patients that could represent stages in the evolution of the disease, the patients could nevertheless be divided into groups according to the predominant central changes.

Apart from the finding noted above that an abnormal chest radiograph was always accompanied by changes on the computed tomography scan, the plain radiograph reports showed no relationship to the computed tomographic findings.
Most of the gallium scan zones were graded as 1 or 2 , and denser uptake tended to be more common at the bases. The six zones graded 3 or 4 on the gallium scans showed diffuse dense central shadowing on the computed tomography scan, but three of nine zones with similar shadowing did not show increased gallium uptake.

Six patients showed defects of xenon uptake and eight showed abnormal xenon retention in at least one zone. Two patients had defective uptake without retention; both had bullae that were evident on the computed tomography scans. There was otherwise no correlation between the results of scintigraphic scanning and those obtained by computed tomography or plain radiography.

\section{Discussion}

One of the principal findings of this study was that the information on the nature and distribution of abnormality within the lungs obtained from the newer imaging techniques was not obtainable from the UICC Cincinnati grading of the chest radiograph, even when this was supplemented by lateral and oblique views.

We found that subpleural shadowing on the computed tomography scan always affected the posterior lower areas unless there was local bulla formation. Our patients with normal chest radiographs after treatment may, of course, differ from those presenting with normal chest radiographs but table 1 shows that our small group could be regarded as a representative subgroup of our previous larger study, at least so far as the plain radiographs are concerned.

We have no information about the relationship of the shadowing we observed to the different patterns of histological change that may be seen in fibrosing alveolitis. Nevertheless, fibrosis in the lungs of patients dying of the disease is known to be more prominent in the subpleural layer. This has been reported for asbestosis, ${ }^{11}$ scleroderma, ${ }^{12}$ and cryptogenic fibrosing alveolitis. ${ }^{13}$ If the variations in subpleural shadowing we detected reflect a similar distribution of histological change in life, the exact site of biopsy would determine the histological picture found. The subpleural lung would show changes dif-

Table 3 Numbers of patients showing shadowing in each central area and type of shadowing

\begin{tabular}{|c|c|c|c|c|c|c|}
\hline & \multicolumn{3}{|c|}{ Right lung } & \multicolumn{3}{|c|}{ Left lung } \\
\hline & Upper & Middle & Lower & Upper & Middle & Lower \\
\hline $\begin{array}{l}\text { Dilated smaller airways of } 1-2 \mathrm{~mm} \text { with } \\
\text { small bullae }(5-10 \mathrm{~mm})\end{array}$ & 1 & 4 & & & 4 & \\
\hline $\begin{array}{l}\text { Larger bullae }(>10 \mathrm{~mm}) \\
\text { Diffuse dense shadowing }\end{array}$ & 3 & 2 & $\begin{array}{l}3 \\
5\end{array}$ & 4 & 1 & $\begin{array}{l}4 \\
4\end{array}$ \\
\hline
\end{tabular}



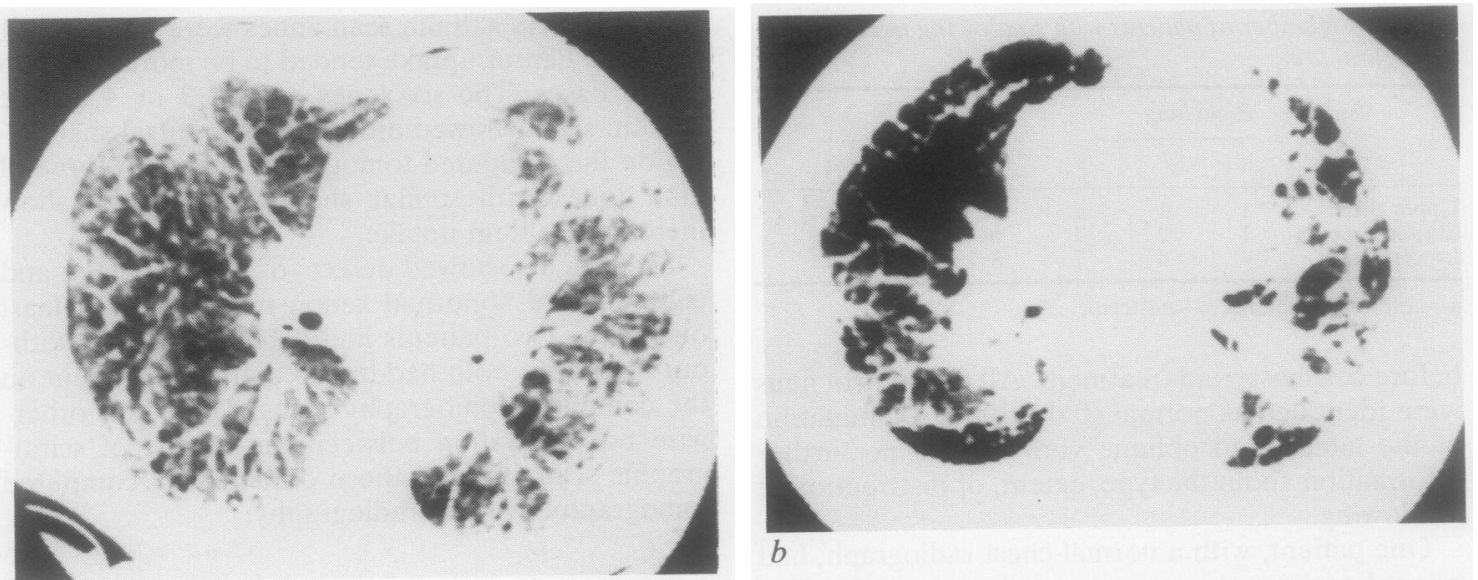

$a(i)$
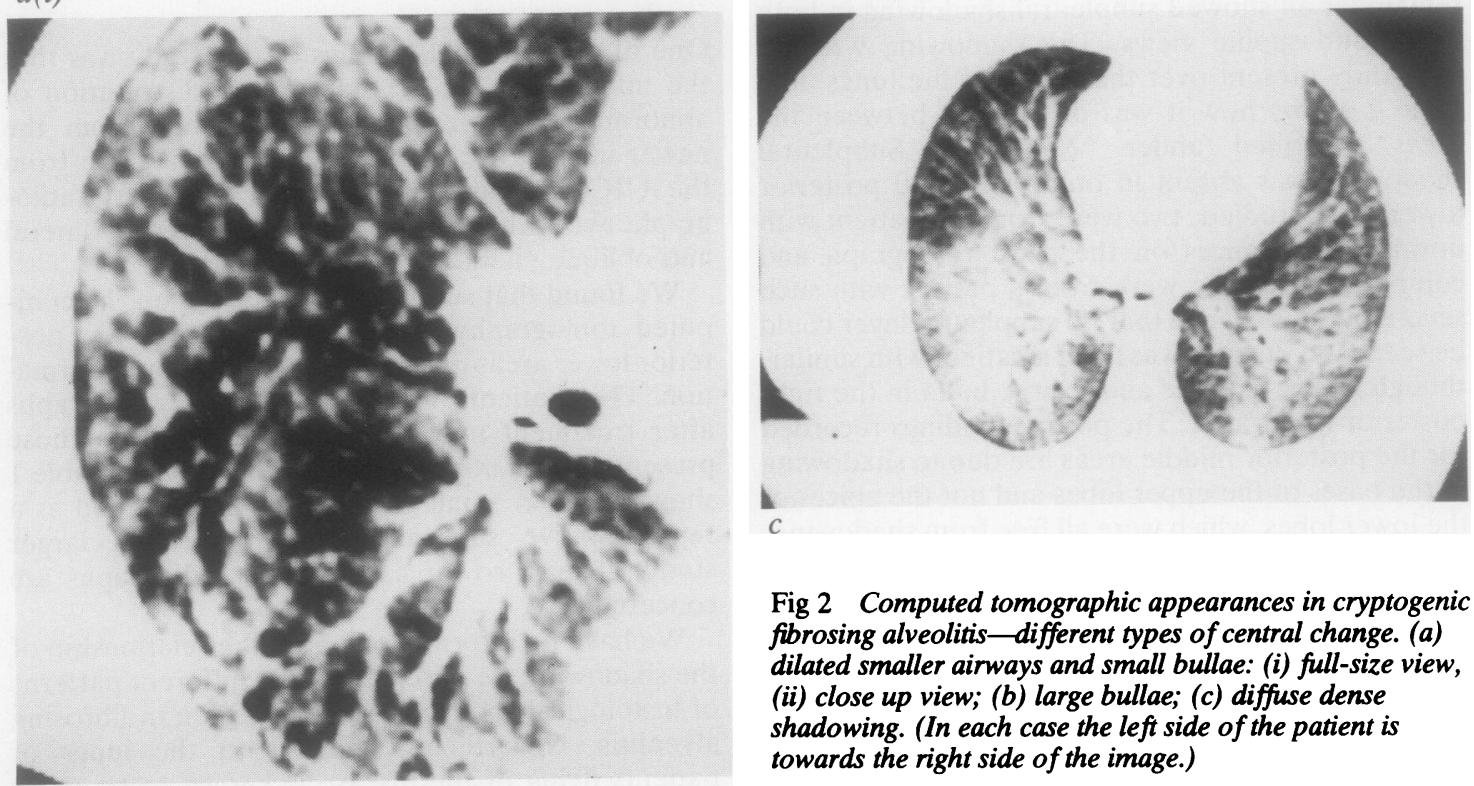

Fig 2 Computed tomographic appearances in cryptogenic fibrosing alveolitis - different types of central change. (a) dilated smaller airways and small bullae: (i) full-size view, (ii) close up view; (b) large bullae; (c) diffuse dense shadowing. (In each case the left side of the patient is towards the right side of the image.)

$a(i i)$

ferent from those in deeper parts, and different subpleural areas would show varying pictures. Some authors have commented that serial sections from the same open lung biopsy specimen may show very different detailed appearances. ${ }^{14}$ is Our trephine biopsy samples from the subpleural lung of the lower lobe therefore came from the site where shadowing predominantly occurs on the computed tomography scan and this could explain why they were found to be useful in predicting prognosis and corticosteroid responsiveness in relatively early cases. For open lung biopsy careful selection of the site would be crucial, as repeatedly explained by Gaensler. ${ }^{41617}$

We did not expect to find a range of patterns of central computed tomographic changes. The practical importance of this cannot be assessed from such a small group of patients but clearly merits further study, and needs to be considered in planning surveys of disease progress or response to treatment.

Gallium scanning divided the patients with diffuse dense central shadowing into two groups, one with greatly increased gallium uptake and one without. Gallium binds to inflammatory cells, notably lymphocytes, and a relationship has been reported between increased uptake, cell counts in bronchoalveolar lavage fluid, and biopsy findings. ${ }^{18}$ We had no reason to think that any of our patients had chest 
infections when they were scanned, and our scans looked similar to the representative one pictured in the paper by Line et al. ${ }^{18}$ Gallium scanning may be of particular help in assessing diffuse central shadowing on the computed tomography scan and response to treatment, but again further study is needed.

The ventilation and perfusion scans added no information to that provided by the other tests. This confirms previous work suggesting such scans are not helpful in the assessment of the disease. ${ }^{19}$

Our results suggest that the efficacy of trephine lung biopsy in the assessment of cryptogenic fibrosing alveolitis may be due to a pattern of distribution of histological change that is reflected in the computed tomographic findings. They also suggest that further investigation of computed tomography and gallium scanning may give new information about the disease.

Our thanks are due to Drs DN Croft and K Tong for their advice and encouragement and for access to the facilities of their departments. Mr A Coleman persuaded the computed tomography computer to work and Miss J Gaunt performed the isotope scans. The departments of medical illustration of St Thomas' and Sandwell Hospitals provided illustrations. The trustees of the endowment funds of St Thomas' Hospital defrayed the travelling expenses of the patients. Professor M Turner-Warwick kindly found time to grade the plain chest radiographs.

\section{References}

' Turner-Warwick M, Strickland B. Diagnosis of diffuse disorders of the lung. In: Emerson $\mathrm{P}$, ed. Thoracic medicine. London: Butterworths, 1981:857-67.

${ }^{2}$ Bateman ED, Turner-Warwick M, Haslam PL, Adelmann-Grill BC. Cryptogenic fibrosing alveolitis: prediction of fibrogenic activity from immunohistochemical studies of collagen types in lung biopsy specimens. Thorax 1983;38:93-101.

${ }^{3}$ Crystal RG, Gadek JE, Ferrans VJ, Fulmer JD, Line BR, Hunninghake GW. Interstitial lung disease: cur- rent concepts of pathogenesis, staging and therapy. Am J Med 1981;70:542-68.

${ }^{4}$ Gaensler EA. Open and closed lung biopsy. In: Sackner MA, ed. Diagnostic techniques in pulmonary disease. Part II. New York: Marcel Dekker, 1980:579-622.

${ }^{5}$ Wright PH, Heard BE, Steel SJ, Turner-Warwick M. Cryptogenic fibrosing alveolitis: assessment by graded trephine lung biopsy compared with clinical, radiographic and physiological features. $\mathrm{Br} J$ Dis Chest 1981;75:61-70.

' Steel SJ, Winstanley DP. Trephine biopsy for diffuse lung lesions. Br Med J 1967;iii:30-2.

${ }^{7}$ Steel SJ, Winstanley DP. Trephine biopsy of the lung and pleura. Thorax 1969;24:576-84.

${ }^{8}$ Steel SJ. Lung biopsy with the high-speed air drill. $\mathrm{Br} J$ Hosp Med 1972; 7:735-8.

${ }^{9}$ International Labour Office. ILO/UC international classification of radiographs of pneumoconioses. Geneva: ILO, 1971.

${ }^{10}$ Kreel L. Computerised tomography using the EMI general purpose scanner. Br J Radiol 1977;50:2-14.

"Gloyne SR. The morbid anatomy of asbestosis. Tubercle 1932;4:445-51.

12 Spencer H. Pathology of the lung. 3rd ed. Oxford: Pergamon Press, 1977:741-6.

${ }^{13}$ Livingstone JL, Lewis JG, Reid L. Diffuse interstitial pulmonary fibrosis, a clinical, radiological and pathological study based on 45 new patients. $Q J$ Med 1964;57:71-103.

14 Roberts WC. Histological observations in idiopathic pulmonary fibrosis. In: Crystal RG, moderator. Idiopathic pulmonary fibrosis, clinical, histological, radiographic, physiologic, scintigraphic, cytologic and biochemical aspects. Ann Intern Med 1976;85:773-6.

15 Hinson KFW. Diffuse pulmonary fibrosis. Hum Pathol 1970;1:275-88.

${ }^{16}$ Gaensler EA, Moister MVB, Hamm J. Open lung biopsy in diffuse pulmonary disease. $N$ Engl J Med 1964;270:1319-31.

${ }^{17}$ Gaensler EA, Carrington CB. Open lung biopsy for chronic diffuse infiltrative lung disease: clinical, roentgenographic and physiological correlations in 502 patients. Ann Thorac Surg 1980;30:411-26.

${ }^{18}$ Line BR, Fulmer JD, Reynolds HY, et al. Gallium 67 citrate scanning in the staging of idiopathic pulmonary fibrosis: correlation with physiologic and morphological features and bronchoalveolar lavage. Am $\mathrm{Rev}$ Respir Dis 1978;118:355-65.

${ }^{19}$ Line BR. Nuclear scanning in idiopathic pulmonary fibrosis. In: Crystal RG, moderator. Idiopathic pulmonary fibrosis; clinical histological, radiographic, physiologic, scintigraphic, cytologic and biochemical aspects. Ann Intern Med 1976;85:779-82. 